\title{
Militância, escrita e vida: a poesia de Deolinda Rodrigues*
}

\author{
Larissa Souza**
}

\section{Resumo}

Nas reflexões sobre a Guerra de Libertação em Angola (1961-1974), a mulher foi observada apenas enquanto vítima histórica ou como figura mítica, a exemplo de Deolinda Rodrigues e sua militância política. Este artigo tem como objetivo questionar esses espaços engendrados, na visitação de suas obras artísticas, compreendendo o protagonismo feminino na guerrilha, como também o processo criativo da subjetividade, por meio da escrita, na reverberação das questões de gênero $e$ suas tensões denunciadas.

Palavras-chave: Mulher, Angola, Guerra, Poesia.

* Recebido em 27 de abril de 2016, aceito em 31 de maio de 2017.

** Doutoranda em Estudos Comparados de Literaturas de Língua Portuguesa pelo Departamento de Letras Clássicas e Vernáculas da Universidade de São Paulo (USP), São Paulo, Brasil. lari.lisboa@gmail.com 
Militancy, Writing and Life:

The Poetry of Deolinda Rodrigues

\begin{abstract}
In the reflections on the Angolan War of Independence (1961-1974) the woman was observed only in her historical life or as a mythical figure, an example of Deolinda Rodrigues and her political militancy. The present article aims to question these spaces engendered, from the study of her artistic works, including not only female protagonism in the guerrilla, but also the critical process of subjectivity, through writing, reverberation of gender issues and their reported tensions
\end{abstract}

Keywords: Woman, Angola, War, Poetry. 


\section{Caminhos epistemológicos para a visibilidade da mulher nas lutas armadas}

As Guerras de Libertação dos países africanos de língua portuguesa trouxeram ao protagonismo histórico não apenas militantes, mas também escritores que denunciavam, sobretudo pela poesia, o regime colonial português. Nomes como Agostinho Neto, em Angola, e José Craveirinha, em Moçambique, são fulcrais. Suas obras, por consequência, foram difundidas e muito estudadas pela crítica. Contudo, poucas são as mulheres lembradas, tanto por suas militâncias nas frontes de batalha, como por seus trabalhos artísticos.

Para Maria Calafate Ribeiro (2004), o século XX representou uma mudança nos paradigmas historiográficos relacionados às guerras, como a perspectiva mais subjetiva da individualidade, além das reflexões sobre o papel da mulher e seus protagonismos.
A crise de masculinidade que esta onda literária, historiográfica e ensaística denunciava, bem como o discurso da psiquiatria relativo ao reconhecimento da neurose de guerra, abriram caminho para que se começasse a pensar a guerra como um fenómeno não exclusivamente masculino (Ribeiro, 2004:09-10).

Porém, a grande quantidade de estudos sobre a mulher nos conflitos africanos desse século debruça-se nos impactos das guerras em suas vidas, principalmente ligados às questões da saúde, a exemplo do HIV. ${ }^{1}$

O livro de Margarida Paredes, Combater duas vezes, mulheres na luta armada em Angola (2015), é um dos poucos

1 O trabalho do Fundo de Desenvolvimento das Nações Unidas para a Mulher (UNIFEM), que resultou no livro Women, War and Peace: The Independent Expert's Assessment on the impact of armed conflict on women and women's role in Peace-building (Rehn \& Sirleaf, 2002), é exemplo paradigmático da maior parte dos estudos que discute a mulher apenas enquanto vítima das guerras, trazendo seus protagonismos em períodos posteriores, vinculados aos desenvolvimentos dos países africanos já independentes. 
exemplos dos fundamentais trabalhos que, atualmente, têm como objetivo a visibilidade das mulheres combatentes em Angola. Em uma entrevista sobre a obra, a pesquisadora afirma,

As mulheres angolanas estiveram em todas as frentes, na luta política e na luta armada. Na luta armada foram muito sacrificadas e correram muitos riscos como provedoras da guerrilha, transportavam armas, plantavam lavras, cuidavam dos guerrilheiros, a logística estava a cargo destas mulheres, a maior parte delas camponesas que depois da independência não foram reconhecidas como guerrilheiras porque não tinham arma e por isso ficaram abandonadas à sua sorte. As mulheres de origem urbana mais escolarizadas também participaram na Luta de Libertação sobretudo na mobilização para a guerrilha, na Educação, na Saúde e algumas como guerrilheiras, no meu livro apresento o testemunho de muitas ex-combatentes que lutaram de armas na mão. Sem a participação das mulheres a Luta de Libertação anticolonial não teria triunfado e Angola não seria independente. ${ }^{2}$

Outro material crítico de grande importância às discussões de gênero nesses países é o livro $A$ mulher em África: Vozes de uma margem sempre presente (Mata; Padilha, 2006). Dentre os diversos artigos, encontra-se o texto intitulado, "A dimensão intelectual de Deolinda Rodrigues" (Gama, 2006:69-72), em que José Gama discute o significativo papel da angolana Deolinda Rodrigues para a história do país.

${ }^{2}$ Entrevista para o portal online Club-K [http://www.clubk.net/index.php?option=com_content\&view $=$ article\&id $=27486$ : margarida-paredes-sem-a-participacao-das-mulheres-a-luta-de-libertacaoanticolonial-nao-seria-angola-nao-seriaindependente\&catid $=17$ :opiniao\&Itemid $=1067 \&$ lang $=$ pt - acesso em: 11 maio 2017]. 
Segundo o autor, o nome de Deolinda Rodrigues ${ }^{3}$ necessita ser reconhecido para além do seu papel de militante do Movimento Pela Libertação de Angola (MPLA) ${ }^{4}$, tendo em vista se tratar de uma mulher múltipla, que caminhou tanto pelos espaços políticos, como pelos artísticos, muitas vezes imbricando-os.

Margarida Paredes (2014) afirma que a militância de Deolinda Rodrigues, tornando-a hoje uma figura mítica na luta de libertação do país, silencia, inclusive, sua história de vida, dentro e fora do movimento político (Paredes, 2014:86).

É possível encontrar, atualmente, duas obras de sua autoria publicadas postumamente, Diário de um exilio sem regresso (Rodrigues, 2003) e Cartas de Langilia e outros documentos (Rodrigues, 2004), que constituem materiais frutíferos aos estudos africanos.

Assim como de muitas mulheres do período, a história de Deolinda Rodrigues ainda carece ser aprofundada. Muitas são as informações incertas sobre sua vida, como a militância no MPLA, $e$ mesmo sua morte nos porões da Polícia Internacional em Defesa do Estado (PIDE), o braço repressor da política portuguesa, responsável pela repressão de todas as formas de oposição ao

3 Deolinda Rodrigues Francisco de Almeida, conhecida por Langidila durante a sua participação na Guerra de Independência de Angola foi a única mulher no Comité Director do Movimento Pela Libertação de Angola (MPLA). Nasceu em Catete, província de Luanda, em 1939. Prima de Agostinho Neto (poeta, primeiro líder do MPLA e primeiro presidente do país), entrou em contato com as questões voltadas à política desde muito cedo. Estudando Sociologia no Brasil e nos Estados Unidos, Rodrigues não concluiu os estudos porque optou pela luta política, em Angola. Escreveu seus primeiros textos ainda menina, nos boletins da revista religiosa metodista, vindo depois a desenvolver trabalhos artísticos voltados à questão política, com poemas e um diário que escreveu no exílio, pouco antes de sua morte, em 1967, assassinada pela Polícia Internacional e Defesa do Estado (PIDE).

${ }^{4}$ O Movimento Pela Libertação de Angola (MPLA) foi, inicialmente, um movimento de luta pela libertação do país, contra o regime colonialista português. Após a independência de Angola, tornou-se um partido político e compôs o primeiro governo do país. O segundo Presidente, José Eduardo dos Santos, ficou no poder por mais de três décadas (1979-2017). 
regime político vigente. Logo, é imprescindível que as informações históricas sobre a sua trajetória sejam revisitadas.

Deolinda Rodrigues tem um papel fundamental à história da mulher em Angola. O dia da mulher angolana, atualmente comemorado em 2 de março, tem como mote a reflexão sobre as cinco militantes que lutaram pela independência do país (Deolinda Rodrigues, Engrácia dos Santos, Irene Cohen, Lucrécia Paim e Teresa Afonso) e que, no ano de 1967, foram presas pela Frente Nacional de Libertação de Angola (FNLA), grupo de oposição ao MPLA, e assassinadas. Essas informações, todavia, ainda geram discussões e questionamentos, como os levantados pela atual deputada do MPLA, Ruth Neto, para quem as militantes não foram mortas nesse dia, mas sim presas. ${ }^{5}$

Em sua tese de doutorado, Margarida Paredes discute as contradições que atualmente existem sobre o dia 2 de março e a escolha dessas mulheres como símbolos da luta nacional, demonstrando as tensões existentes entre os divergentes grupos de resistência:

O dia 2 de março, "Dia da Mulher Angolana", data em que Deolinda Rodrigues foi feita prisioneira no campo militar da FNLA em Kinkuzu, é feriado nacional. Apesar da visibilidade das comemorações, nem todas as mulheres angolanas se reveem nesta heroína do MPLA e as mulheres de outros partidos políticos recusam comemorar o dia 2 de março como "Dia da Mulher Angolana", reivindicando uma data que não esteja conotada ao partido no governo. Esta contestação à imposição das heroínas a todas as mulheres angolanas enquadra-se noutras lógicas de contestação que também questionam símbolos nacionais como a bandeira e o hino nacional, identificados com o MPLA (Paredes, 2014:88).

5 Texto citado a partir do site Angonotícias [http://www.angonoticias.com/Artigos/item/12663/deolinda-rodrigues-nao-foimorta-em-2-de-marco-diz-ruth-neto - acesso em: 11 maio 2017]. 
Tem-se ciência, portanto, que essas ainda são discussões complexas, demonstrando a importância de que mais estudos sobre essas mulheres sejam realizados.

No campo da crítica literária, a análise de alguns textos de Deolinda Rodrigues, cuja biografia ainda apresenta uma série de lacunas, também é tarefa árdua e inovadora. Felizmente, algumas de suas obras poéticas foram salvaguardadas e, dessa forma, é possível refletir sobre os temas norteadores de seus textos, não apenas fortemente concatenados à luta política de Angola, mas também às questóes de gênero, tencionando o papel da mulher nas frontes de batalha e na cultura do país.

No livro Diário de um exilio sem regresso (Rodrigues, 2003), algumas reflexões são fundamentais para compreender os poemas de Deolinda, visto que em seu discurso é possível observar as angústias na luta armada, relacionadas ao preconceito de gênero por parte dos camaradas de luta, o que também inclui as outras mulheres,

Disseram-me que não vou para Ghana porque sou mulher e o Barden não respeita senhoras. Esta discriminação só por causa do meu sexo, revolta-me. Se me apanho fora deste MPLA erudito e masculino, não volto em breve (Rodrigues, 2003:57) (...) Uma das companheiras tem receio de mim e evita-me por eu ser mandona, ter a mania de dar ordens e não saber cozinhar (Rodrigues, 2003:70).

A posição contestatória de Rodrigues denuncia o espaço de luta política, "erudito e masculino", refutando, inclusive, os lugares-comuns do feminino, como o doméstico, "saber cozinhar", ou mesmo a passividade, contrária ao espírito da liderança, "mania de dar ordens".

Segundo Maria Salete Daros de Souza (2015), a participação de mulheres nas esferas políticas e militar coloca em questão a desconstrução do pensamento androcêntrico estabelecido, visto que: 


\begin{abstract}
Primeiramente, torna estremecido e questionável o estereótipo de gênero que atribui às mulheres o lugar "da paz", em contraposição ao lugar "da guerra" destinado aos homens na estabelecida dicotomia "mulher pacífica $\mathrm{x}$ homem violento". Ao vencer a barreira do estereótipo que naturaliza homens $e$ mulheres, relativizando-o na constatação da experiência vivida por mulheres, impõe-se o confronto com uma realidade de mulheres de "carne $e$ osso", como diz Portolés (2012), capazes de viver muito além das representações que lhe são atribuídas (Souza, 2015:114).
\end{abstract}

No artigo "Narrativas de Guerrilha do Feminino", Cristina Scheibe Wolff (2009), no estudo comparativo entre os discursos de ex-combatentes do chamado Cone Sul na América Latina, reflete que as mulheres que não se reconheciam enquanto feministas, mas sim como militantes da esquerda política, percebiam menos as diferenças existentes entre homens $e$ mulheres nas lutas políticas, enquanto as que se consideravam feministas, essas discussões eram mais presentes.

Essa é uma interessante reflexão, consoante com o posicionamento de Deolinda Rodrigues, visto que, ainda que a mesma nunca tenha se intitulado como feminista, Margarida Paredes acredita que ela tenha sido uma feminista "avant a lettre" , porque já trazia em seus discursos as tensões de gênero presentes nos espaços da guerrilha.

\title{
Deolinda Rodrigues: da figura mítica à mulher escritora
}

Assim como na escrita biográfica, é possível observar na poesia de Deolinda Rodrigues muitas das inquietudes discorridas. No poema "A mamã", a escritora apropria-se dos recursos estilísticos e ideológicos comuns ao período, a exemplo da metáfora da mãe como símbolo da união entre os povos

6 [http://www.club-k.net/index.php?option=com_content\&view =article\&id=27486: margaridaparedes-sem-a-participacao-das-mulheres-a-luta-de-libertacao-anticolonial-nao-seria-angola-naoseria-independente\&catid =17:opiniao\&Itemid =1067\&lang=pt - acesso em: 11 maio 2017]. 
africanos $^{7}$, porém desconstruindo sua imagem, subvertendo a figura de linguagem para denunciar os conflitos existentes entre os camaradas de luta,

\author{
África \\ Mamã África \\ Geraste-me no teu ventre \\ nasci sob o tufão colonial \\ chuchei teu leite de cor \\ cresci \\ atrofiada mas cresci \\ juventude rápida \\ como a estrela que corre \\ quando morre o nganga. \\ Hoje sou mulher \\ não sei já se mulher se velhinha \\ mas é a ti que venho \\ África \\ Mamã África. \\ Tu que me geraste \\ não me mates \\ não praguejes um rebento teu, \\ senão \\ não tens futuro. \\ Não sejas matricida \\ Sou Angola, a tua Angola. \\ Não te juntes ao opressor \\ ao amigo do opressor \\ nem a teu filho bastardo. \\ Eles caçoam de ti. \\ Caíste na ratoeira \\ enganada
}

\footnotetext{
7 A metáfora da mãe, pode ser encontrada em inúmeros textos poéticos, obras de escritores da época, a exemplo de Viriato da Cruz, Agostinho Neto e Alda Lara, como parte de ideologias relacionadas ao pan-africanismo e aos movimentos da negritude.
} 


\author{
não distingues o verdadeiro do falso \\ no teu candidato e secular vigor \\ cegaste, \\ e agora és tu \\ África \\ Mamã África \\ que dás força ao irmão bastardo \\ para asfixiar-me \\ azagaiar-me pelas costas. \\ O opressor, o amigo do opressor \\ o teu filho bastardo \\ (também tu, Mamã África?) \\ divertir-se-ão \\ ao ouvir-me expirar. \\ Mas África \\ Mamã África \\ P'lo amor de coerência \\ Inda quero crer em ti.
}

(apud García, 1998:57-58)

No poema, a expressão "Mamã África", que poderia ser inicialmente interpretada como acolhimento ou afetividade, inscreve-se com outro tom em seu discurso: uma mãe que pare o irmão, mas também o inimigo; é a terra que cultiva tanto a luta pelas independências, como suas incoerências, a exemplo da corrupção e das violações sociais nas frontes de batalha.

O eu-lírico do poema, a mulher, filha dessa mãe a quem se reporta, levanta a sua trajetória no solo materno, nascendo já no "tufão colonial" e com "crescimento atrofiado" pelo contexto em que viveu, entre guerras e violências que a impediram de se desenvolver. Por isso, uma juventude rápida, como a "estrela que corre/quando morre um Nganga" - termo da língua bantu que significa curandeiro espiritual, o médico tradicional das comunidades africanas. Identificando-se como mulher, o eu-lírico não sabe se é ainda jovem ou se idosa. Pelas atrofias da vida, as 
marcas corpóreas rasuram idades e o corpo em chagas confunde o tempo.

A mulher atrofiada, com feridas que carrega pela vida, agora clama para que sua mãe não a mate. A progenitora, a MãeÁfrica de todos os irmãos, representa, assim, um perigo. Por isso, ela deseja que essa mãe não se "pragueje", ou seja, não se amaldiçoe, para que tenha um futuro, que não seja uma matricida.

É interessante observar que, etimologicamente, o termo matricídio significa "assassinato da própria mãe" (Bechara, 2011:815). Logo, além do medo do filicídio, o ato da mãe matar o próprio filho, o eu-lírico também teme que a mãe seja matricida, negando a própria vida, a libertação do continente. Como consequência, a filha traz, novamente, a marca de sua identidade, como se a clamar pela consciência materna: "Sou Angola, a tua Angola".

A partir de conselhos, o eu-lírico sugere que sua mãe não se junte aos opressores e aos filhos bastardos, não legítimos, ou seja, os que não estão na autêntica luta pelas independências, os desertores. Essa mãe "cega", que se une aos inimigos para asfixiar os que lutam pela libertação, apropria-se de alguns instrumentos, como a azagaia, uma lança curta usada por caçadores, para apunhalar seus filhos legítimos, pelas costas. E todos, inclusive ela, a mamã, divertir-se-ão com a morte daqueles que sonharam $e$ lutaram em prol da mãe acolhedora.

Somente na última estrofe parece existir alguma esperança de que a mãe volte a ter certa coerência e compreenda que os caminhos do opressor, do filho bastardo, só atrofiam as conquistas e a vida dos africanos. Ainda assim, o eu-lírico não quer desistir de sua genetriz, sua terra, pois acredita que a luta se faz necessária e os tempos de hipertrofias chegarão.

A "Mamã", ao mesmo tempo filicida e matricida, demonstra que a mãe-psicótica, em meio a um pós-parto de guerras $e$ desesperanças, constitui-se como uma mãe doente, metáfora crítica das novas nações que se constroem problemáticas, não 
fertilizando a terra de sonhos e esperanças, pelas contradições dos próprios movimentos de luta pelas independências.

O discurso denunciador e contestatório de Deolinda Rodrigues no poema é, nesse sentido, precursor em Angola, visto que a historiografia literária no país, até então, enaltecia a metáfora da mãe nas construções poéticas, a partir de uma perspectiva fortemente utópica, não discutindo as contradições, conflitos e tensões entre os movimentos de luta do país. ${ }^{8}$

A crítica da artista é comparável ao discurso do escritor Ahmadou Kourouma, da Costa do Marfim, no livro O Sol das Independências (Kourouma, 1995), publicado em 1968, considerado o primeiro romance crítico quanto aos processos de independências no continente africano, refletindo sobre o proselitismo, a alienação das novas elites africanas no poder, os conflitos tribais que se intensificaram etc. Conduta crítica que só será possível observar em Angola nas décadas posteriores, a exemplo dos textos do escritor Pepetela. ${ }^{9}$

Logo, é possível afirmar que, além de Deolinda Rodrigues ser avant la lettre nas questões de gênero, como trouxe Margarida Paredes, ela também é avant la lettre em trazer para a literatura angolana as contradições dos processos de independência. Seu texto, dessa forma, já reverbera uma visão pós-colonial (Mata, 2013).

Segundo Inocência Mata, o termo pós-colonial pressupõe "uma nova visão da sociedade que reflete sobre a sua condição periférica, tanto em nível estrutural como conjuntural" (Mata, 2013:31). O termo não tem haver, necessariamente, com uma linearidade cronológica da história. Sua temporalidade tem

8 No artigo "Guerra e Paz em Angola" (Agualusa, 2004), o escritor angolano José Eduardo Agualusa discute as contradições do MPLA nos mais de 40 anos no poder, citando a experiência contestatória do escritor Viriato da Cruz, figura emblemática que rompeu com o MPLA, exilando-se na China até sua morte. Contudo, os poemas de Viriato da Cruz tinham como discussão a questão da valorização da cultura angolana, diferente dos textos de Deolinda Rodrigues.

9 O livro A Geração da Utopia (Pepetela, 1992) é um dos maiores exemplos. 
relação com o agenciamento crítico dos sujeitos dentro do processo de descolonização.

O jornalista Reginaldo Silva, para o jornal Rede Angola ${ }^{10}$, afirma:

De todos os documentos que tenho tido acesso relativamente a este tempo passado, nenhum como estes manuscritos de Deolinda Rodrigues são tão frontais na crítica interna ao funcionamento do MPLA e muito particularmente ao posicionamento de alguns dos seus principais dirigentes da época (...).

Percebe-se, dessa forma, a crítica lúcida de Deolinda, numa perspectiva pós-colonial, o que também inclui as discussões raciais. Margarida Paredes (2014) levanta a hipótese de que alguns materiais publicados no período pela Organização da Mulher Angolana (OMA), de cuja criação Deolinda Rodrigues participou, tenham sido escritos por ela, justamente porque caracterizam o seu posicionamento, além dos diálogos, por cartas, com Martin Luther King, indicando o conhecimento das lutas pelos direitos civis nos Estados Unidos e os movimentos de mulheres negras.

Por isso, a pesquisadora afirma que Deolinda Rodrigues já refletia sobre o feminismo negro antes mesmo dessas discussões terem sido teorizadas no continente, indicando, como exemplo, o texto "O papel da mulher na luta armada", documento da OMA de 1965 ,

A mulher, sendo uma parte essencial do povo, está em primeiro lugar na discriminação. [...] As mulheres pretas em todo o mundo compreendem bem esta verdade porque elas são discriminadas duas vezes: por serem mulheres e por causa da cor da pele [...] Hoje nós as angolanas sabemos que há muito trabalho que nós podemos fazer para avançar

\footnotetext{
${ }^{10}$ Publicado no jornal independente Rede Angola, em 04 de março de 2015 [http://www.redeangola.info/opiniao/o-racismo-de-deolinda-rodrigues/ - acesso em: 11 maio 2017].
} 
a nossa luta, [...] até o fazer parte das milícias nas sanzalas e pegar em armas para lutar contra os portugueses no maquis (Anexo 3, Arquivo Lúcio Lara, Associação Tchiweka) (apud Paredes, 2014:98).

No poema "Inquirindo", percebe-se um discurso autobiográfico, já no momento em que Deolinda Rodrigues está inserida no Esquadrão Kamy, coluna guerrilheira treinada em 1966 por internacionalistas cubanos, com o objetivo de levar reforços para as fronteiras do Congo e também no "Destacamento Cienfuegos", a primeira grande unidade guerrilheira do MPLA em Brazzaville, capital da República do Congo. O grupo era integrado por duzentos homens $e$ apenas cinco mulheres. $O$ insucesso da missão ocasionou na prisão e morte da escritora.

Carrascos de upistas espia de tugas prostituta

mulher metida em política aqui estou etiquetada disso inquirindo o fim deste pesadelo inquirindo cada vez que soa o passo bruto, ronca o jeep militar, a corneta toca formatura geral. Colam-me o guarda à porta. Será o pelotão do talho, a minha vez, a dele um camarada na margem direita o capitão conga vem levar-nos agora ou nunca?

Aqui estou eu inquirindo sempre inquirindo

Na ilha do inferno não há túnel. Vietname acabou abuso yankee. Colômbia retomou caminho da dignidade.

Outra mina rebentou em Pretória.

Acima de tudo 


\author{
Ripanzu \\ (com Cienfuegos, Kamy e o outro) \\ avança. \\ Consertando o estragado \\ varrendo o colonialista \\ edificando o lógico. \\ Brazza transmitiu a marcha do Kamy? \\ Inquirindo \\ inquirindo p'ra manter \\ a luta constante \\ entre o suicídio à espreita \\ e este louco redemoinho \\ até a manhã chegar, \\ sair viva do campo da morte \\ e poder ser útil \\ na liberdade de escolha \\ da responsabilidade a tomar \\ a liberdade de ação \\ para realizá-la.
}

(apud García, 1998:59-60)

O título do poema, "Inquirindo", aponta, com o emprego de uma palavra de impacto, o contexto intrínseco de guerras e lutas a que Deolinda Rodrigues pertencia. "Inquirir", verbo transitivo direto, tem algumas significações, tais como: "1. Tentar obter informações sobre (um assunto); 2. Fazer pergunta(s); questionar; 3. Interrogar oficialmente, com caráter político ou jurídico" (Bechara, 2011:737). Trata-se de uma palavra que conduz a outras, complementares, tais como: inquisição, inquisidor ou inquisitivo. Inquirir, dessa forma, constitui-se como um verbo que enquizila.

Ademais, a palavra no poema está conjugada no gerúndio. Sugere-se, assim, um questionamento contínuo. Mas de que interrogatório se trata? $\mathrm{Na}$ primeira estrofe do texto, alguns elementos parecem dar pistas sobre o inquérito: "os carrascos upistas". A União das Populações de Angola (UPA) tornou-se, posteriormente, a Frente Nacional pela Libertação de Angola 
(FNLA), que lutou durante as Guerras de Libertação e Civil contra o MPLA.

Em seu estudo sobre a literatura de autoria feminina nos sistemas culturais dos países africanos de língua portuguesa, a Professora Tânia Macedo (2010) faz uma breve ponderação sobre esse poema:

Os amargos anos de luta contra o colonialismo também produziram textos de combatentes, como os realizados pela angolana Deolinda Rodrigues que, no cárcere, pouco antes de sua execução, no poema "Inquirindo" afirma em um texto dramaticamente autobiográfico (Macedo, 2010:6).

O poema traduz um inquérito oficial, no qual o inquisidor é a UPA e o inquirido, a militante do MPLA, considerada "prostituta", porque também rasura o espaço público masculino de luta, enquanto mulher. Por isso, a militante no poema está etiquetada, afinal, seu corpo é um ultraje, e precisa de uma taxação para que seja sempre lembrada a sua diferença.

"Inquirindo", na marca do gerúndio como um inquérito $e$ uma luta sem fim, a combatente traça parte da situação específica em que vivia, como militante do Esquadrão Kamy. Como ela havia sido capturada e entregue à UPA, os lugares de luta não deixavam de representar a "ilha do inferno", visto que sempre existia um inquisidor. Desse modo, o desejo maior era o de sair viva do campo de batalha, ou o "campo da morte", para poder ser útil novamente ao movimento de libertação. ${ }^{11}$

Rodrigues, assim, traz as questões de gênero quando o poema discute a utilidade do corpo militante, da mulher, em que ele realmente só existe na liberdade de escolha $e$ da responsabilidade da ação. Enquanto o início do poema se constrói a partir do discurso inquisitório, adjetivando a mulher militante como "prostituta", o poema termina com um tom de resistência,

\footnotetext{
${ }^{11}$ A obra Heroínas de Angola, da cubana Limbânia Jimènez Rodriguez, traz em detalhes esses dois acontecimentos, $e$ o papel das mulheres militantes na luta pela libertação de Angola (Rodriguez, 2014).
} 
pela liberdade da mulher em poder decidir sobre os caminhos que seguirá pela vida. Assim, o ultraje desse corpo inscrito aponta para a marca de uma ação de rebeldia e militância nas questões voltadas às mulheres.

Os exemplos de conflitos em outras partes do mundo citados no poema, como a Colômbia - "Colômbia retomou caminho da dignidade", o Vietnã - "Vietname acabou abuso yankee" - e a África do Sul - "Outra mina rebentou em Pretória" - também caracterizam o texto dentro de uma perspectiva póscolonial, visto que as críticas são refletidas como marcas dos processos históricos que modificaram e redefiniram as relações entre os países e os continentes, a exemplo das duas guerras mundiais, e a possibilidade de pensar nas lutas de forma internacionalista, integrando-as, "varrendo o colonialista".

Os poemas de Deolinda Rodrigues trazem um discurso forte, com escolhas lexicais diversas, demonstrando tanto o domínio pela norma culta da língua portuguesa, como pelos vocábulos das línguas locais, com a inserção de palavras da família linguística bantu.

A militância no MPLA e a vida privada da mulher confundem-se na poesia de Rodrigues. Logo, sua escrita é o espaço entre a ação política contra o colonialismo, os desertores e os exercícios contestatórios sobre o lugar da mulher na sociedade angolana. Seus textos, dessa forma, são registros históricos da guerrilha do país, com a importância de um discurso sob a ótica de uma mulher.

Deolinda Rodrigues, portanto, representa todas as mulheres que se inscreveram na militância, na poesia e na vida, com um legado testemunhal sobre suas condições, conflitos e experiências durante o período colonial em Angola, para que assim fossem mais bem compreendidas as conquistas que, posteriormente, surgiriam. 


\section{Referências bibliográficas}

AgualuSA, José E. Guerra e Paz em Angola. In: Revista Kosmopolis. Festa Internacional de la literatura. Barcelona, 2004.

Bechara, Evanildo. Dicionário de Língua Portuguesa Evanildo Bechara. Rio Grande do Sul, Nova Fronteira, 2011.

GAMA, José. A dimensão intelectual de Deolinda Rodrigues. In: PADILHA, Laura Cavalcante; MATA, Inocência (org.). A mulher em África. Vozes de uma margem sempre presente. Lisboa, Colibri, 2006, pp.69-72.

GarCía, Xosé Lois. Antologia da poesia feminina dos PALOP (Países Africanos de Língua Oficial Portuguesa). Galiza, Edicíons Laiovento, 1998.

Kourouma, Ahmadou. O Sol das Independências. São Paulo, Nova Fronteira, 1995 [Tradução: Marisa Murray].

MACEDO, Tania. Da voz quase silenciada à consciência da subalternidade: A literatura de autoria feminina em países africanos de língua oficial portuguesa. Revista Mulemba, $n^{\circ} 2$, Rio de Janeiro, Universidade Federal do Rio de Janeiro, 2010 [http://setorlitafrica.letras.ufrj.br/mulemba/artigo.php?art=artigo_2 _1.php - acesso em: 4 mar 2016].

MATA, Inocência. A Literatura africana e a crítica pós-colonial. Reconversões. Manaus, UEA Edições, 2013.

MATA, Inocência; PADILHA, Laura Cavalcante (org.). A mulher em África. Vozes de uma margem sempre presente. Lisboa, Colibri, 2006.

PAREDES, Margarida. Deolinda Rodrigues, da Família Metodista á Família MPLA, o papel da cultura na política. Cadernos de Estudos Africanos $\mathrm{n}^{\circ} 20$, Lisboa, Instituto Universitário de Lisboa, 2010, pp.11-26.

- Mulheres na luta armada em Angola: Memória, cultura e emancipação. Tese (Antropologia ), Instituto Universitário de Lisboa (ISCTE-IUL), Lisboa, Portugal, 2014.

. Combater duas vezes. Mulheres na luta armada em Angola. Portuga, Verso da História, 2015.

Pepetela. A Geração da Utopia. Lisboa, Publicações Dom Quixote, 2005. 
REHN, Elisabeth; SIRLEAF, Ellen J. Women, War and Peace: The Independent Experts' Assessment on the impact of armed conflict on women and women's role in peace-building. Nova Iorque, Fundo de Desenvolvimento das Nações Unidas para a Mulher (UNIFEM), 2002.

RIBEIRO, Margarida C. África no Feminino. As mulheres portuguesas e a Guerra Colonial. Revista Crítica de Ciências Sociais, $\mathrm{n}^{\circ}$ 68, Coimbra, Centro de Estudos Sociais da Universidade de Coimbra, 2004, pp.7-29.

RoDRIGUES, Deolinda. Diário de um exílio sem regresso. Luanda, Nzila, 2003.

. Cartas de Langidila e outros documentos. Luanda, Nzila, 2004.

Rodriguez, Limbânia Jiménez. Heroínas de Angola. Luanda, Mayamba, 2014.

SouZA, Maria Salete D. Cabe o amor no relato da Guerra? Testemunhos femininos e o atlântico pós-colonial. Tese ( Letras ), Universidade Federal de Santa Catarina, Florianópolis, 2015.

WolfF, Cristina S. Narrativas de Guerrilha no Feminino (Cone-Sul 19601985). Revista de História da UNISINOS, $\mathrm{n}^{\circ}$ 13, vol. 2, Rio Grande do Sul, 2009, pp.124-130. 